\title{
HOXA9 Positive
}

National Cancer Institute

\section{Source}

National Cancer Institute. HOXA9 Positive. NCI Thesaurus. Code C150643.

An indication that expression of HOXA9 has been detected in a sample. 